\title{
2020 reflected: part 2
}

Stephen Hancocks OBE
Editor-in-Chief

The BDJ Upfront section includes editorials, letters, news, book reviews and interviews. Please direct your correspondence to the News Editor, Kate Quinlan at k.quinlan@nature.com. Press releases or articles may be edited, and should include a colour photograph if possible.

$\mathrm{H}$ ere I look at the current effects the coronavirus pandemic is having on the practice of dentistry and what changes this might mediate in the future.

There is not a business in the UK, and probably the world, that hasn't in some way or another been affected by the pandemic. The business of dentistry is no exception but what is interesting is that if I were to write 'the business of medicine' it wouldn't sound quite right would it? The pharmaceutical industry, yes; personal protection equipment manufacturers, yes; the business of medicine, no. Here, I believe, is the nub of the realisation that the pandemic has made us ponder, if not for the first time then certainly in a starker and more pressing way than ever before. The overwhelming majority of dentistry is carried out in general dental practice as a business, a model replicated worldwide. The advent of the pandemic and the many associated human restrictions imposed by governments sent the business models into a tailspin. In the UK the differences between private practices and those with NHS contracts were laid as bare as they have ever been. The former were by and large 'on their own', the latter had at least some government support. There are no rights or wrongs but there are divisions and their exposure will make for some deep thought over future practice funding no matter for which model the owner opts.

What will also influence the way in which such decisions are to be made, or enforced, will be changes in attitudes to prevention. I have no doubt that short memories will prevail and individually we will forget and fail to be motivated to step up prevention. Nevertheless, in many areas of self-care, collectively we will have to begin to take prevention far more seriously than previously if we are to preserve oral, and general, health. Less caries means the whole profile of restorative dentistry changes; aerosol generating procedures are reduced with concomitantly lower levels needed of personal protective equipment, face masks, respirators, ventilation and so forth, not to mention antibiotics, painkillers and child general anaesthetics for extractions.

The BDJ has for some years now been a supporter of, and advocate for minimum intervention dentistry. Described under various terms the basic philosophy remains the same as detailed in our three themed issues on the subject and as promoted by organisations such as CariesCare International and the Alliance for a Cavity Free Future which provide practical application of the principles. It would be too cliched to suggest that the pandemic will automatically trigger a wholesale move toward these methods in the mother of invention) which will become accepted and expected adjuncts to oral care.

These are important changes in dental practice of the future because of patient trust in us. Despite the coronavirus mayhem I believe that trust has not only been retained but has been strengthened. I stated here recently that to the best of my knowledge there had been no reported cases of patients or dental team members worldwide contracting COVID-19 through dental treatment; and no one has as yet sent me such evidence. If so, this means that not only are our current levels of additional caution and protection working but that, probably, even the previous stringent levels of cross-infection control were significantly robust.

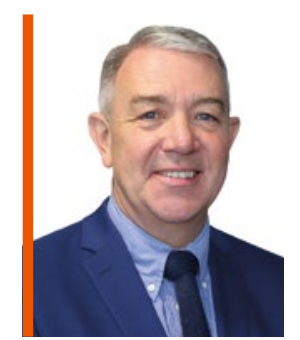

\section{'Trust has not only been retained but has been strengthened'}

dental practice. However, it is not farfetched to suggest that it has hastened their consideration and strengthened the case for the economic application of their evidence-based procedures. And what of our patients in all of this? Wise men of decades ago foretold that any main changes in the delivery of dental care would not be propagated by the profession but by public, consumer expectation. A prophesy made flesh through social media, online reviews and internet searches. Knowledge of, interest in and demand for implants, tooth whitening and yes, even prevention have been driven by technological developments which we have all witnessed. Again, these have been enhanced further by teledentistry, online medical history completion and consent and a raft of other innovations (necessity is
Some things will slide back, lessen and revert. We will once again be able to meet and mingle at dental exhibitions, lectures and events, we will participate in fewer webinars and online conferences. We will rediscover and be relieved by the opportunities to travel once again. But practice owners who believe that we will relax back into the world as it was this time last year will be seriously wrongfooted. For the majority, who will conjure and embrace the legendary ingenuity of dentists to find ways to cope and triumph, the future actually looks remarkably bright and even, I believe, rather exciting. We have a long way to go but the negatives of 2020 could yet be the turning points that properly herald twenty-first century dental practice.

https://doi.org/10.1038/s41415-020-2497-3 